\title{
Change, technology and higher education: are universities capable of organisational change?
}

\author{
Stephen Marshall* \\ University Teaching Development Centre, Victoria University of Wellington, PO Box 600, \\ Wellington, New Zealand
}

(Received 30 January 2010; final version received 30 September 2010)

Technology and change are so closely related that the use of the word innovation seems synonymous with technology in many contexts, including that of higher education. This paper contends that university culture and existing capability constrain such innovation and to a large extent determine the nature and extent of organisational change. In the absence of strong leadership, technologies are simply used as vehicles to enable changes that are already intended or which reinforce the current identity. These contentions are supported by evidence from e-learning benchmarking activities carried out over the past five years in universities in the United States, the United Kingdom, Australia and New Zealand.

Keywords: organisational change; e-learning maturity model

\section{Introduction}

Educational technology is a field based on change. (Surrey 2005, 933)

Investment in technology systems by universities is driven by the expectation that increased use of technology will improve the quality and flexibility of learning (Bates 2001; Bush 1945; Cuban 2001; DfES 2003; Oppenheimer 2003; Ryan et al. 2000). This investment has been supported by the widespread adoption of Learning Management Systems and the computerisation of key administrative functions (Hawkins and Rudy 2006, 52; Zemsky and Massy 2004), and the maintenance of an effective technology infrastructure remains a key strategic focus for university leaders (Allen and Seaman 2008; McCarthy and Samors 2009).

However, while information technology systems have become mainstream, and even strategically irrelevant for many activities (Carr 2003; Chester 2006), changes in the experience of learning and teaching enabled by technology are less apparent. As educational technologists we share a common belief that technology can significantly improve the experience of learners and teachers. That belief has seen the field of educational technology progress from an initial naivety that simply introducing technology would improve the learning experience. Many institutions have attempted variations on early adopter innovation projects, invested in substantial infrastructures, and consequently developed an awareness of the need for formalised and systematic

\footnotetext{
*Email: Stephen.Marshall@vuw.ac.nz
} 
professional development. Beyond the focus on the individual teacher we also have the rhetoric of organisational change, perhaps best expressed by Fullan:

The answer to large-scale reform is not to try to emulate the characteristics of the minority who are getting somewhere under present conditions ... Rather, we must change existing conditions so that it is normal and possible for a majority of people to move forward. $(2001,268)$

This awareness of the role of organisational change is not recent, with the need to go beyond the pedagogy and technology to consider organisational aspects (Bates 2001; Ryan et al. 2000), leadership (Hanna 1998; Reid 1999) and systems (Ison 1999; Laurillard 1997, 1999; Peters 1999) recognised. Those leading change in universities need to balance technological, academic and administrative concerns (Jones 2003; McCarthy and Samors 2009). These include the strategy and culture of the organisation (Laurillard 1997; Reid 1999; Remeyni, Sherwood-Smith, and White 1997), resource utilisation (Karelis 1999), sustainability (Strauss 2002; Young 2002), scalability and reusability (Bain 1999; Boyle 2003; IEEE 2002).

This paper explores evidence from e-learning benchmarking activities carried out over the past five years in universities in the United States, the United Kingdom, Australia and New Zealand in an attempt to understand the nature of university change in response to technology.

\section{Organisational change as a theoretical construct}

Simple understandings lead to general rules to be applied in all situations; complicated understandings suggest that situations differ and that reliance on experiences of the past may prove dysfunctional. [...] Only complicated understandings can see the many and conflicting realities of complicated situations. (Birnbaum 1988, 209)

Change in large complex organisations can be described as operating at multiple levels: process, systems, structures, organisations and institutions (Seel 2007; Waks 2007). Process and systems change happens frequently as new ideas, technologies or capabilities become available within an organisation and can be driven by individuals or small groups within the organisation. When these changes are not disruptive to the work of other systems and structures, they can be described as interoperable change. Historically, structural and organisational change has been managed as a discontinuous process with organisations undergoing a period of instability and change before returning to periods without change.

Birnbaum (1988) suggests that change can occur more effectively if universities are managed according to the principles of cybernetics, what Stafford Beer called the science of effective organisation. Structures within the organisation are then organised in a loosely coupled manner (Weick 1976).

Christensen, Anthony, and Roth (2004) identify three types of organisational change. 'Sustaining' changes are ones that improve the function of the organisation in ways that are consistent with previous activities. Putting lecture handouts on a Learning Management System rather than expecting students to pick up a physical copy from an office is an example of a sustaining change. 'Disruptive' changes create new markets or reshape existing ones. 'Low-end disruptive' changes can occur when the existing product exceeds the needs of some consumers. For example, many people 
obtaining degrees might be well served by less comprehensive providers with fewer subject options but also significantly lower fees. 'New market disruptive' change can occur when consumers are limited by the capability or complexity of existing products. Online delivery of degrees is potentially a new market disruption, although the lack of success of virtual universities to date illustrates the challenge facing providers attempting to realise that potential (Cunningham et al. 2000; Zemsky and Massey 2004).

Disruptive change is problematic for dominant organisations as the natural tendency is to protect existing structures and activities, particularly when those are currently seen as successful. It is important to emphasise that technology is by default neither sustaining nor disruptive in nature. The use of the Internet to deliver courses can be a low-end disruptive change to universities when implemented by an organisation to undercut the costs of obtaining a basic degree; or simply a sustaining change when used by an existing distance university to supply electronic rather than paper documents. Christensen, Anthony, and Roth $(2004,126)$ contend that the use of the Internet to deliver university education has failed in many cases as it has been used to deliver an inferior experience in competition to the existing model to the same group of students, rather than to current 'non-consumers'. They suggest that such failures, rather than being the result of poor course design, are the result of a misidentification of the market for such courses.

\section{Must universities change and should change be a response to technology?}

An obvious question to ask is whether universities need to and should change in response to external forces, including technology. As an institution of society (Waks 2007), the university has existed for centuries. A university degree is considered an essential qualification for many young people, and accredited degrees offer many international opportunities for those who wish to travel and work. The stability of the institution and the apparent resistance to change may reflect the value to society of the institution in its current form.

One obstacle to change may be the lack of strong evidence that technology is benefiting educational outcomes for students (Conole, Oliver, and Harvey 2000; GAO 2003; Kenny 2001; Means et al. 2009; Radloff 2001; Taylor 2001a; Zemsky and Massy 2004). While this is most probably a result of poor research design and the challenge of collecting empirical evidence of improvement in student learning outcomes, it does make it harder to justify the expense and disruption of change to sceptical organisation leaders, colleagues and other stakeholders.

There is also the need to consider the purpose of change. Much of the recent change evident in universities has been driven by financial accountability for public funds. The university has a range of purposes, participants and audiences, all of whom apply pressures for change to better suit their needs or resist changes that disrupt their perception of the university as an institution (Kerr 2001; Marginson 2004). Perkins $(1973,12)$ recognised that these conflicting purposes challenge universities, preventing the use of simple measures of performance such as profit, while there is also the internal conflict between structures that most efficiently support research with those that integrate research with education.

Despite these internal complexities, the forces driving change are such that universities cannot ignore the implications. Governments are acutely conscious of the need to educate adults failed by existing institutions (HCPAC 2009), and internationally 
there are many countries seeking solutions to the problem of educating a population without the resources or opportunities of university education (Daniel, Kanwar, and Uvalic-Trumbic 2009). Christensen's model predicts that the risk for universities lies in the emergence of new institutions and organisations that meet the needs of these non-participants (Christensen, Anthony, and Roth 2004). It is a short step from serving this group to more cheaply and efficiently serving significant proportions of the university's current student population.

Beyond the social drivers for change, there is also the rapid pace of technological change. Our society is likely to experience the same level of technological change in the next 100 years as it experienced in the past 20,000 years (Kurzweil 2005, 50).

Taylor (2001b) observed that the challenge facing universities trying to best use technology for education is not so much about the innovation itself. Key is the execution of the change; the need for the organisation to rapidly evolve to sustain the execution of change at the same increasing pace at which new technologies are developed.

The ubiquity of technology, combined with ever decreasing costs, means that the use of the technology itself is increasingly not a distinguishing factor for organisations, but rather the quality of that use and the way it advances the goals of a changeresilient organisation become essential to success (Carr 2003; Hamel and Välikangas 2003). Organisational leaders need to distinguish the products of change, the visible uses of technology, from the processes that result in their use. Demers $(2007,34)$ identifies from the work of DiMaggio and Powell (1983) three mechanisms that drive institutional change and which can influence processes for change within organisations:

- coercive isomorphism, which explains change as a consequence of formal or informal pressures imposed on organisations externally;

- mimetic isomorphism, which describes the tendency for organisations to adopt 'standard' or popular approaches in uncertain times; and

- normative isomorphism, which is change that is driven by professionalism and the emergence of 'legitimated professional practices' that result in pressure for organisations to conform because their staff are able to draw on organised professional networks and professional standards that guide their activities.

The last of these, 'normative isomorphism', is the form most consistent with the values of the collegial university institution. 'Coercive isomorphism' is the form that is most visible through the pressures placed by governments on (particularly public) universities to demonstrate economic benefits of their programmes and to minimise costs. 'Mimetic isomorphism' is seen in the restructuring work of consultants (McKinnon, Walker, and Davis 1999) and the adoption by universities of popular management fads.

Coercive isomorphism and mimetic isomorphism both represent significant challenges to the identity of universities as collegial, academic organisations. Resisting these forms of change behaviour requires strong leadership, an organisation with a strongly expressed collective identity, or both.

Change within an organisation can be described as top-down (driven by management), bottom-up (reflecting emergent or participatory-driven change), or combinations of the two. Bottom-up initiatives are generally driven by individual 'early adopters' (Rogers 1995), and while substantial resources have been invested in such projects, wider adoption and use requires more than resources: leadership, systems 
and a supportive climate for change are essential (Southwell et al. 2005). Strong leadership, aware of the dynamics and culture of their organisation, is vital, enabling creation of systems for change and providing the resources needed to enact new ideas, but even with leadership change can be challenging for universities. Birnbaum (1988, 205 ) noted that leaders can drive significant change from the top most easily in universities that:

- are in a state of acknowledged crisis;

- are small;

- are conspicuously out of date; or

- have autocratic leadership.

Other than small institutions, these conditions cannot be seen as particularly desirable or consistent with the collegiality of the university institution. Clearly, universities need change strategies operating simultaneously and synergistically at multiple levels (Moore 2006; Russell 2009; Southwell et al. 2005). Maturity models such as the e-learning Maturity Model described below attempt to make explicit these strategies and capture the extent to which they are evident in the activities of individual organisations.

\section{Analysing the capability of universities to change with the e-learning Maturity Model}

The e-learning maturity model (eMM) (Marshall and Mitchell 2002; http:// www.utdc.vuw.ac.nz/research/emm/) is a quality improvement framework based on the ideas of the Capability Maturity Model (Paulk et al. 1993) and the Software Process Improvement and Capability Determination (SPICE) framework (El Emam, Drouin, and Melo 1998; SPICE 2002). The eMM framework measures the capability of institutions to sustainably engage in technology-supported learning and teaching, and visualises that capability in a way that assists leaders and managers using that information to undertake systematic and targeted improvements in their organisation's e-learning activities. The eMM is intended to go beyond benchmarking to actively support organisational change activities. The maturity model theoretical construct is explicitly designed to encourage self-reflection and the improvement of organsational activities.

Since the initial development, the eMM has been developed, refined and validated through a series of projects conducted in New Zealand (Marshall 2005, 2006a; Marshall and Mitchell 2006), Australia (Marshall, Mitchell, and Beames 2009), the United Kingdom (Sero 2007; Bacsich 2008; University of London 2008) and the United States (Marshall, Udas, and May 2008). The eMM assesses the ability of an organisation to ensure that e-learning design, development and deployment is meeting the needs of the students, staff and the organisation itself on five dimensions (Figure 1). Rather than levels, which imply a hierarchical model of process improvement where capability is assessed and built in a layered and progressive manner, the concept underlying the eMM's use of dimensions is holistic capability. Each process is assessed from the synergistic perspectives of 'Delivery', 'Planning', 'Definition', 'Management' and 'Optimisation'.

The eMM divides the capability of institutions to sustain and deliver e-learning into 35 processes grouped into five major categories or process areas that indicate a 


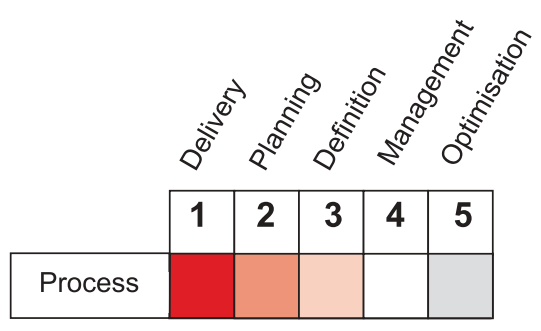

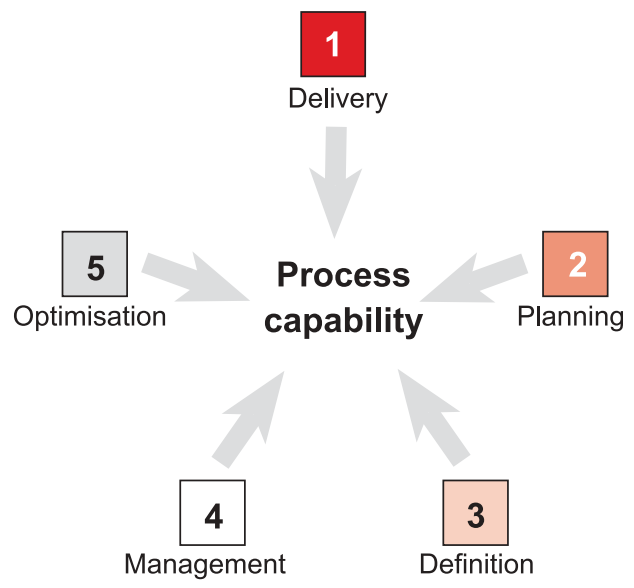

Figure 1. eMM process dimensions.

shared concern. It should be noted, however, that all of the processes are interrelated to some degree, particularly through shared practices and the perspectives of the five dimensions. Each process in the eMM is broken down within each dimension into practices that define how the process outcomes might be achieved by institutions (Figure 2). The practice statements attempt to capture directly measurable activities for each process and dimension. The processes and practices are derived from an extensive review of the literature, international workshops and experience from their application (Marshall 2006b, 2008).

The eMM promotes organisational change in this framework at three main levels. The most explicit is the Optimisation dimension, which is explicitly assessing systematic change in the organisation. Beyond this, experienced practitioners undertake assessments using an adequacy scale that can easily evolve to reflect better knowledge about effective technology use. Finally, the processes and practices of the model are evolving, changing in subsequent versions to reflect the experience and evidence from international assessments and the literature (Marshall 2006b, 2008).

Figure 3 shows a summary of the capabilities of a number of international universities. The organisations shown range from very large to very small, from strongly teaching focused through to prestigious research-dominated universities. All of these universities describe themselves as modern organisations keen to take best advantage of technology to advance all of their activities. As a sample, they illustrate the range of organisational capability for the adoption and use of technology within the international university sector (Marshall 2009). The capability assessments shown here focus on e-learning activities and do not directly assess other types of learning and teaching.

The patterns of stronger capability (dark shading) and weaker (light shading) can be observed from this matrix. Each box represents a further summary of detailed practices for each dimension of the individual processes (rows) that can be used by

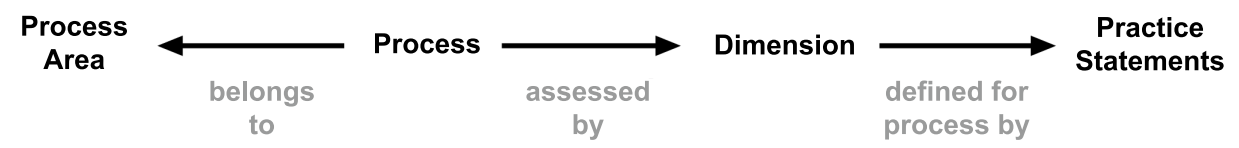

Figure 2. Relationships between processes, practices and dimensions. 


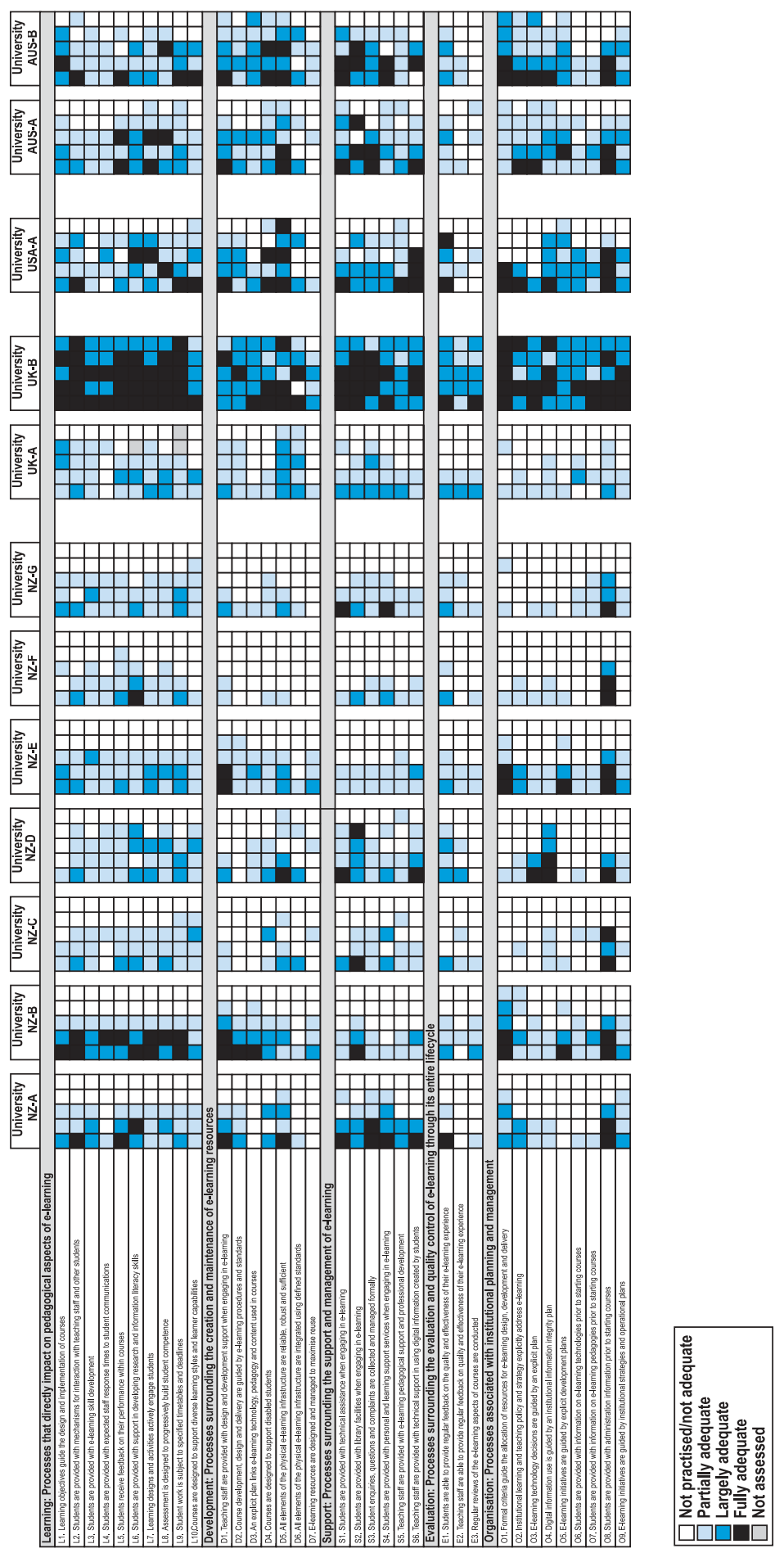

Figure 3. eMM capabilities of international universities (Marshall 2009). 
institutions as checklists or plans for improvement. Each column represents a single institution in summary, with five sub-columns for each of the five dimensions.

Stronger capability can arise for a number of reasons. It may reflect existing systems essential to all forms of delivery. For example, process O8 (Figure 4) is relatively strong in all of these institutions, as a result of common administrative processes being used by these universities regardless of the mode of delivery. The strength apparent in process S2 (Figure 4) is similarly a result of the move to support technology use by all library users, not just those engaging in technology-mediated learning. In both of these cases, however, the lack of capability in the Optimisation dimension is evident, due to the absence of activities aimed at systematically improving the experience of technology-mediated learners.

Stronger capability may also be a result of activities being under the direct control of individual staff able to influence the experience of the students through their own work. This is apparent in the generally stronger capability of the Delivery dimension of the Learning process area and arises from the actions of individual teachers within their courses and programmes. The absence of capability in most institutions through the other dimensions shows the lack of institutional engagement with these same issues.

Finally, stronger capability may also reflect dedicated investment of resources aimed at the process activities. This can be seen in the relative strength of process D5 (Figure 5), which arises from the consistent and substantial investment in Learning Management Systems and the supporting infrastructure seen in most universities. This contrasts with process D6 (Figure 5), where the comparatively weaker capability results from the lack of formal engagement with standards and a dependence on a specific vendor's products as default solutions.

Weaker capability can reflect the reality that specific processes are not useful as currently formulated (i.e. process D7), but can also illustrate the absence of particular activities relevant to organisational change. The very weak capability of the Evaluation processes and the Management dimension of all processes result from the widespread lack of consultation with staff and students regarding their experiences of technology-mediated learning. Most institutions appear to operate on the implicit assumption that their systems and tools are sufficient and if there is an issue someone will complain.

\begin{tabular}{|c|c|c|c|c|}
\hline \multicolumn{5}{|c|}{$\begin{array}{l}\text { 08: Students are provided with administration } \\
\text { information prior to starting courses }\end{array}$} \\
\hline & 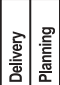 & 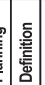 & & 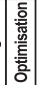 \\
\hline \multicolumn{5}{|l|}{ University NZ-A } \\
\hline University NZ-B & & & & \\
\hline University NZ-C & & & & \\
\hline University NZ-D & & & & \\
\hline University NZ-E & & & & \\
\hline University NZ-F & & & & \\
\hline University NZ-G & & & & \\
\hline University UK-A & & & & \\
\hline University UK-B & & & & \\
\hline University USA-A & & & & \\
\hline University Aus-A & & & & \\
\hline University Aus-B & & & & \\
\hline
\end{tabular}

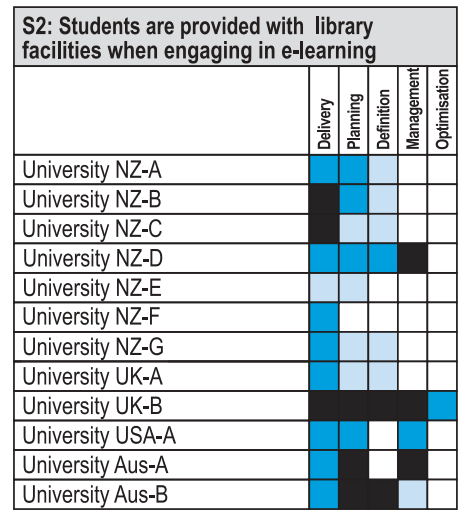

Figure 4. University process O8 and S2 capabilities (Marshall 2009). 

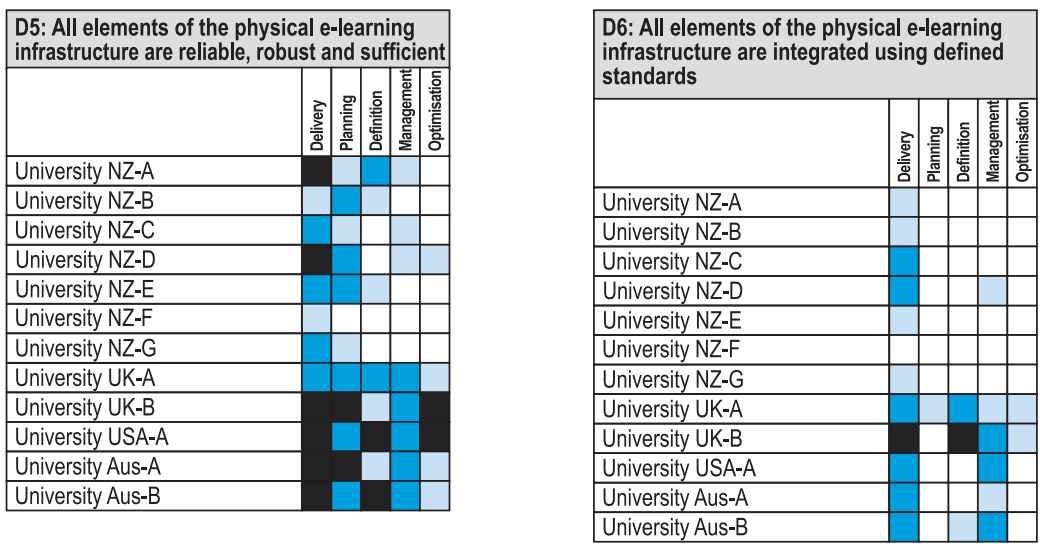

Figure 5. University process D5 and D6 capabilities (Marshall 2009).

The assessment data shown here can also be used to reflect on the types of organisational change these universities have demonstrated, and to suggest where opportunities and challenges await in the future. Figure 3 potentially represents a form of organisational change snapshot. The capability assessments summarising the impact of change that has occurred to date as these universities have worked to integrate technology into their activities, overlaid on the generic capabilities intrinsic to each organisation.

The absence of a formal change mechanism promoting technology for learning and teaching is evident in the lack of capability in the Definition dimension for most of these universities. This is a result of there being few formal processes, policies or staff development opportunities addressing the implications of technology use by these organisations. Individual institutions show different patterns of engagement with technology suggesting the change approach being used (either explicitly or implicitly). University NZ-A has a distinctly stronger capability in the Delivery and Planning dimensions of the Support process area, consistent with an approach driven by a focus on student support, independent of specific courses and programmes. In contrast, university NZ-B shows stronger capability in the Learning and Development areas, reflecting a formal design and development approach driven by a specialist team. The absence of capability in the Definition dimension for NZ-B, however, illustrates a common problem with the use of dedicated technologists, as there is no evidence of a mechanism transferring expertise to all teaching staff, limiting the impact by the size of the team of support staff.

There is very little evidence of a culture of critical self-reflection within the organisational assessments, and this is shown in the almost complete absence of capability in the Optimisation dimension of most institutions. This is possibly linked to the weak Evaluation process and Management dimension capability noted above, but also probably reflects the lack of attention by university leaders to these areas. This lack of leadership is also evident in the weak capabilities for processes $\mathrm{O} 9$ and $\mathrm{O} 2$ (Figure 6) in most of the institutions. This lack of strategic context is possibly one of principle reasons that technology has not driven organisational change, despite the opportunities to do so (McCarthy and Samors 2009). 

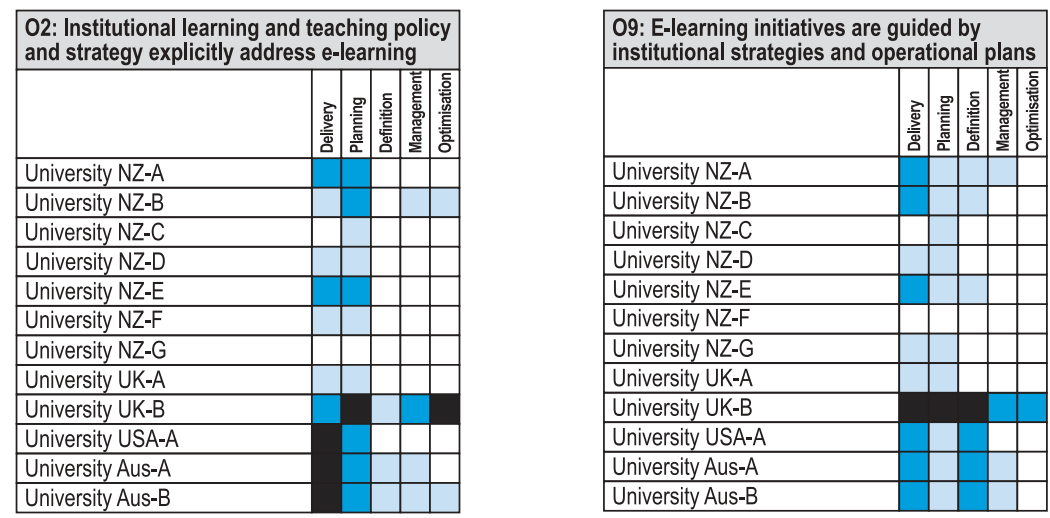

Figure 6. University process O2 and O9 capabilities (Marshall 2009).

\section{Conclusions}

Future technological developments will probably change the nature of the student experience and possibly disrupt the university as an institution of society, making existing organisational models and pedagogies unsustainable (Hedberg 2006). This paper contends that, more commonly and for the immediate future, the change resulting from new technologies depends on the change culture and leadership decisions of the individual universities.

The eMM is designed as a tool for supporting change informed by the benchmarking analysis. The analysis of the visualisations presented above provides the first step of a potential change process. The audience for this analysis encompasses all of the stakeholders, and the visual approach adopted is intended to make the initial questioning of organisational capability a simple pattern-matching activity. Once a pattern has been identified, the eMM provides the details of the underlying practices that both provide a framework for assessment, but also a starting point for the development of action plans (Marshall 2006b). The practices are defined so as to enable organisations considerable flexibility in how the assessed outcome is achieved, supporting a range of pedagogies, technologies and other significant characteristics of the learning and teaching environment.

The eMM does not, however, provide a specific, pre-defined, mechanism for organisational change. The intention is to ensure that change is well-informed, facilitated by the ability to see areas of organisational strength and weakness, and that the impact of change initiatives be apparent in subsequent assessments. The underlying model of organisational maturity is descriptive of the characteristics of more effective institutions, but does not define or measure the path taken to achieve that outcome.

The evidence from the eMM assessments presented in this paper suggest that, to date, decisions have been made primarily with the intention of engaging in 'sustaining' and 'mimetic' forms of change and that universities as organisations as yet show little capability to disrupt their existing educational models. An ongoing priority for the eMM research is testing this analysis, working with organisations changing to take advantage of new technologies, examining the ways which that work is seen in eMM capability assessments and verifying the utility of the eMM framework as a changeoriented quality improvement tool. 
Laurillard (1997) identified over a decade ago the need to examine the limitations of current practices carefully so as to incrementally improve capability, but the lack of engagement with students and staff seen in these assessments and the weak assessments in the Optimisation dimension offer little evidence of critical self-examination. The UK Government, the Australian Government and the New Zealand Government have repeatedly imposed various performance indicator-reporting requirements on universities, but there is no evidence of a culture of systematic self-improvement driving the examination and use of technologies for learning and teaching. Most of the universities assessed here have supported staff engaging in bottom-up, early adopter innovation, but have failed to provide systems and environments that result in wider adoption of successful ideas (Moore 2006; Russell 2009; Southwell et al. 2005).

The implications for those interested in promoting change within the university as an institution are challenging. A clear avenue for further action is finding ways that the experiences of students and staff can be used to frame future technology supported organisational and pedagogical change. Beyond this there is a need for clearly articulated goals for change supported by, rather than led or in response to technology, or coerced by external drivers. Reasons for change enabled by and making effective use of technologies are needed that are relevant to the organisations and to the staff and students who, collectively with the leadership, create the university (McCarthy and Samors 2009).

As a societal institution, universities need to grapple with the two types of disruptive change identified by Christensen, Anthony, and Roth (2004). University leaders need to be alert to the ways by which other organisations are meeting the educational needs of people who are not university students, and avoid the myopia common to dominant organisations (Levitt 1975). Universities may not be responsible for meeting the needs of all adult 'non-consumers' of higher education, but all stakeholders in the university institution need to be aware that others meeting those needs might also better meet the needs of many existing university students. New 'low-end' providers may lack prestigious reputations, and may well compromise some aspects of quality university learning, but only a very few universities can depend on their reputation and not respond to the demands of governments and students to deliver a more flexible and less expensive education.

\section{References}

Allen, I.A., and J. Seaman. 2008. Staying the course: Online education in the United States, 2008. Needham, MA: Sloan Consortium. http://sloanconsortium.org/publications/survey/ staying_course (accessed August 28, 2010).

Bacsich, P. 2008. Higher Education Academy/JISC e-learning benchmarking phase 2 overview report. Report to the Higher Education Academy. http://elearning.heacademy.ac.uk/ weblogs/benchmarking/wp-content/uploads/2008/04/BenchmarkingPhase2_BELAreport. pdf (accessed August 28, 2010).

Bain, J. 1999. Introduction to the special edition. Learner-centred evaluation of innovations in higher education. Higher Education Research and Development 18, no. 1: 57-75.

Bates, T. 2000. The continuing evolution of ICT capacity: The implications for education. In The changing face of virtual education, ed. G.M. Farrel, 29-46. Vancouver: The Commonwealth of Learning.

Birnbaum, R. 1988. How colleges work: The cybernetics of academic organization and leadership. San Francisco, CA: Jossey-Bass.

Boyle, T. 2003. Design principles for authoring dynamic, reusable learning objects. Australian Journal of Educational Technology 191: 46-58. 
Bush, V. 1945. As we may think. Atlantic Monthly August: 101-8. http://www.theatlantic. com/doc/194507/bush (accessed February 25, 2009).

Carr, N. 2003. IT doesn't matter. Harvard Business Review 81, no. 5: 5-12.

Chester, T.M. 2006. A roadmap for IT leadership and the next ten years. Educause Quarterly 29. http://www.educause.edu/apps/eq/eqm06/eqm0626.asp (accessed August $28,2010)$.

Christensen, C.M., S.D. Anthony, and E.A. Roth. 2004. Seeing what's next: Using the theories of innovation to predict industry change. Boston, MA: Harvard Business School Press.

Conole, G., M. Oliver, and J. Harvey. 2000. Toolkits as an approach to evaluating and using learning material. Paper presented at the 17th Annual ASCILITE Conference, in Southern Cross University, Coffs Harbour, Australia.

Cuban, L. 2001. Oversold and underused: Computers in the classroom. Cambridge, MA: Harvard University Press.

Cunningham, S., Y. Ryan, L. Stedman, S. Tapsall, K. Bagdon, T. Flew, and P. Coaldrake. 2000. The business of borderless education. Canberra, Australia: Department of Education, Training and Youth Affairs, Commonwealth of Australia.

Daniel, J.S., A. Kanwar, and S. Uvalic-Trumbic. 2009. Breaking higher education's iron triangle: Access, cost and quality. Change: The Magazine of Higher Learning 41: 30-5.

Demers, C. 2007. Organizational change theories: A synthesis. Los Angeles, CA: Sage Publications.

DfES. 2003. Towards a unified e-learning strategy. London: Department for Education and Skills. http://www.dcsf.gov.uk/consultations/downloadableDocs/towards $\% 20 \mathrm{a} \% 20$ unified \%20e-learning\%20strategy.pdf (accessed February 25, 2009).

DiMaggio, P., and W. Powell. 1983. The iron cage revisited: Institutional isomorphism and collective rationality in organizational fields. American Sociological Review 48: $147-60$.

El Emam, K., J.-N. Drouin, and W. Melo. 1998. SPICE: The theory and practice of software process improvement and capability determination. Los Alamitos, CA: IEEE Computer Society.

Fullan, M. 2001. The new meaning of educational change. New York: Teacher's College Press.

GAO. 2003. Military transformation: Progress and challenges for DOD's Advanced Distributed Learning programs. United States General Accounting Office report GAO-03-393. Washington, DC: United States General Accounting Office.

Hamel, G., and L. Välikangas. 2003. The quest for resilience. Harvard Business Review 81, no. 9: 52-63.

Hanna, D.E. 1998. Higher education in an era of digital competition: Emerging organizational models. Journal of Asynchronous Learning Networks 2, no. 1: 66-95.

Hawkins, B.L., and J.A. Rudy. 2006. Educause core data service: Fiscal year 2006 summary report. Boulder, CO: Educause.

Hedberg, J.G. 2006. E-learning futures? Speculations for a time yet to come. Studies in Continuing Education 28: 173-85.

HCPAC. 2009. Widening participation in higher education: Fourth report of session 200809. House of Commons Public Accounts Committee. http://www.publications.parliament.uk/pa/cm200809/cmselect/cmpubacc/226/9780215526557.pdf (accessed August 28, 2010).

Ison, R. 1999. Applying systems thinking to higher education. Systems Research and Behavioural Science 16: 107-12.

Jones, S. 2003. Measuring the quality of higher education: Linking teaching quality measures at the delivery level to administrative measures at the university level. Quality in Higher Education 9: 223-9.

Karelis, C. 1999. Education technology and cost control: Four models. Syllabus Magazine 12, no. 6: 20-28.

Kenny, J. 2001. Where academia meets management: A model for the effective development of quality learning materials using new technologies. Paper presented at the 18th ASCILITE Conference, in Biomedical Multimedia Unit, The University of Melbourne, Australia. 
Kerr, C. 2001. The uses of the university. 5th ed. Cambridge, MA: Harvard University Press.

Kurzweil, R. 2005. The singularity is near. New York: Penguin.

Laurillard, D. 1997. Applying systems thinking to higher education. Milton Keynes, UK: Open University.

Laurillard, D. 1999. A conversational framework for individual learning applied to the learning organisation and the learning society. Systems Research and Behavioural Science 16: $113-22$.

Levitt, T. 1975. Marketing myopia. Harvard Business Review 38, no. 4: 2-14.

Marginson, S. 2004. University futures. Policy Futures in Education 2, no. 2: 159-74.

Marshall, S. 2005. Determination of New Zealand tertiary institution e-learning capability: An application of an e-learning maturity model: Report on the e-learning maturity model evaluation of the New Zealand tertiary sector. Report to the New Zealand Ministry of Education. Wellington, New Zealand: Victoria University of Wellington.

Marshall, S. 2006a. New Zealand tertiary institution e-learning capability: Informing and guiding e-learning architectural change and development. Report to the New Zealand Ministry of Education. Wellington, New Zealand: Victoria University of Wellington.

Marshall, S. 2006b. eMM version two process guide. Wellington, New Zealand: Victoria University of Wellington.

Marshall, S.J. 2008. What are the key factors that lead to effective adoption and support of e-learning by institutions? In Proceedings of HERDSA 2008. Rotorua, New Zealand: HERDSA.

Marshall, S. 2009. Crossing the ditch: Applying the e-learning maturity model to Australian institutions. Paper presented at the 26th ASCILITE Conference, December 6-9, in Auckland, New Zealand.

Marshall, S., and G. Mitchell. 2002. An e-learning maturity model? Paper presented at the 19th ASCILITE Conference, in Auckland, New Zealand.

Marshall, S., and G. Mitchell. 2006. Assessing sector e-learning capability with an e-learning maturity model. Paper presented at the Association for Learning Technologies Conference, in Edinburgh, UK.

Marshall, S., G. Mitchell, and S. Beames. 2009. Report on the ACODE eMM Project. Report to the Australasian Council on Open and Distance Education. http://www.utdc.vuw.ac.nz/ research/emm/acode/20090625ACODEReport.pdf (accessed August 28, 2010).

Marshall, S., K. Udas, and J. May. 2008. Assessing online learning process maturity: The elearning maturity model. Paper presented at the 14th Annual Sloan-C International Conference on Online Learning, November 6-7, in Orlando, FL.

McCarthy, S.A., and R.J. Samors. 2009. Online learning as a strategic asset: Volume 1: A resource for campus leaders. Association of Public and Land-grant Universities. http:// www.aplu.org/NetCommunity/Document.Doc?id=1879 (accessed August 28, 2010).

McKinnon, K.R., S.H. Walker, and D. Davis. 1999. Benchmarking: A manual for Australian universities. Canberra, ACT: Commonwealth of Australia.

Means, B., Y. Toyama, R. Murphy, M. Bakia, and K. Jones. 2009. Evaluation of evidencebased practices in online learning. Washington, DC: US Department of Education.

Moore, G.A. 2006. Crossing the chasm. Rev. ed. New York: HarperCollins Publishers.

Oppenheimer, T. 2003. The flickering mind. New York: RandomHouse.

Paulk, M.C., B. Curtis, M.B. Chrissis, and C.V. Weber. 1993. Capability maturity model, version 1.1. IEEE Software 10: 18-27.

Perkins, J.A. 1973. Organization and functions of the university. Journal of Higher Education 43, no. 9: 679-91.

Peters, G. 1999. A systems failures view of the UK National Commission into Higher Education report. Systems Research and Behavioural Science 16: 123-31.

Radloff, A. 2001. Getting online: The challenges for academic staff and institutional leaders. In Proceedings of the 18th ASCILITE Conference, 11-13. Melbourne: Biomedical Multimedia Unit, The University of Melbourne.

Reid, I.C. 1999. Beyond models: Developing a university strategy for online instruction. Journal of Asynchronous Learning Networks 3: 19-31.

Remenyi, D., M. Sherwood-Smith, and T. White. 1997. Achieving maximum value from information systems: A process approach. New York: John Wiley and Sons.

Rogers, E.M. 1995. The diffusion of innovations. 4th ed. New York: Simon and Schuster. 
Russell, C. 2009. A systemic framework for managing e-learning adoption in campus universities: Individual strategies in context. ALT-J, Research in Learning Technology 17, no. 1: 3-19.

Ryan, Y., B. Scott, H. Freeman, and D. Patel. 2000. The virtual university: The internet and resource-based learning. London, UK: Kogan Page.

Seel, R. 2007. The nature of organisational change. Higher Education Academy. http:// www.heacademy.ac.uk/assets/York/documents/ourwork/changeacademy/2007/ CA018D_Seel_NatureOfOrganisationalChange.doc (accessed August 28, 2010).

Sero. 2007. Baseline study of e-activity in Scotland's colleges. Report to the Scottish Funding Council, July. http://www.sfc.ac.uk/web/FILES/learningfiles/sero_e_activity_study.pdf (accessed August 28, 2010).

Southwell, D., D. Gannaway, J. Orrell, D. Chalmers, and C. Abraham. 2005. Strategies for effective dissemination of project outcomes. Canberra, Australia: Commonwealth of Australia.

SPICE. 2002. SPICE software process assessment version 1.00. http://www-sqi.cit.gu.edu/ spice/ (accessed December 18, 2002).

Strauss, H. 2002. The right train at the right station. Educause Review 37, no. 2: 30-6.

Surrey, D.W. 2005. Editorial. British Journal of Educational Technology 36: 933-5.

Taylor, J. 2001a. 29 steps to heaven? Strategies for transforming university teaching and learning using multimedia and educational technology. Milton Keynes, UK: The Open University.

Taylor, J. 2001b. Fifth generation distance education. Keynote Address presented at the 20th ICDE World Conference, 1-5 April, in Düsseldorf, Germany.

University of London. 2008. Benchmarking eLearning at the University of London: Report from the steering group. London, UK: University of London. http://www.londoninternational.ac.uk/quality/comte_zone/sys_tech_sub/stsc2/documents/stsc2_3.pdf (accessed August 28, 2010).

Waks, L. 2007. The concept of fundamental educational change. Educational Theory 57: 277-96.

Weick, K.E. 1976. Educational organizations as loosely coupled systems. Administrative Science Quarterly 21: 1-19.

Young, B.A. 2002. The paperless campus. Educause Quarterly 252: 4-5.

Zemsky, R., and W.F. Massey. 2004. Thwarted innovation: What happened to e-learning and why. West Chester, PA: The Learning Alliance at the University of Pennsylvania. 